Cortical Sensory Organization

Multiple Auditory Areas 


\section{Cortical Sensory Organization Edited by Clinton N. Woolsey}

Volume 1: Multiple Somatic Areas Volume 2: Multiple Visual Areas Volume 3: Multiple Auditory Areas 


\title{
Cortical Sensory Organization
}

\author{
Volume 3 \\ Multiple Auditory Areas
}

Edited by

Clinton N. Woolsey

University of Wisconsin, Madison, Wisconsin

Humana Press - Clifton, New Jersey 


\section{Library of Congress Cataloging in Publication Date}

Main entry under title:

Cortical sensory organization.

Includes bibliographies and indexes.

Contents: v. 1. Multiple somatic areas

- v. 3. Multiple auditory areas.

1. Cerebral cortex. 2. Senses and sensation.

I. Woolsey, Clinton N.

QP383.C67 599.8'04182 81-81433

ISBN-13: 978-1-4612-5819-3 e-ISBN-13: 978-1-4612-5817-9

DOI: $10.1007 / 978-1-4612-5817-9$

AACR2

(c) 1982 The HUMANA Press Inc.

Softcover reprint of the hardcover 1st edition 1982

Crescent Manor

P. O. Box 2148

Clifton, N. J. 07015

All rights reserved.

No part of this book may be reproduced, stored in a retrieval system, or transmitted, in any form or by any means, electronic, mechanical, photocopying, microfilming, recording, or otherwise without written permission from the Publisher 


\section{Table of Contents}

Contents of Other Volumes.......................

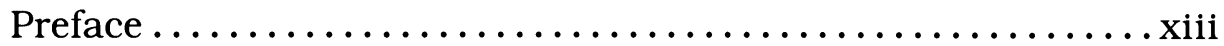

Chapter 1

The Auditory Cortex: Patterns of Corticocortical

Projections Related to Physiological Maps in the

Cat ..................................1

Thomas J. Imig, Richard A. Reale and John F. Brugge

1. Tonotopic Organization............................

1.1. Field A I...................................4

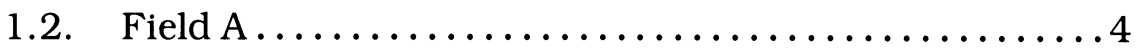

1.3. Fields $\mathrm{P}$ and VP.............................

1.4. Isofrequency Contours....................... 8

1.5. The Peripheral Auditory Belt $\ldots \ldots \ldots \ldots \ldots \ldots \ldots . . .9$

2. Corticocortical Conections Related to Best-

Frequency Maps ..............................9

2.1. Relationship between Best Frequencies

Located at the Sources and Terminations of

Corticortical Connections.....................9

2.2. Topography of Projections: Patches and

Bands ...................................15

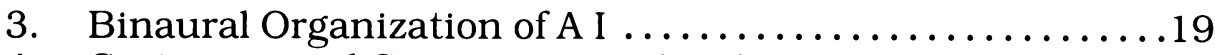

4. Corticocortical Connections Related to Binaural

Maps.......................................23

4.1. Patterns of Callosal Innervation in A I.............23

4.2. Patterns of Ipsilateral Corticocortical

Terminations in A I. ........................36

Abbreviations ......................................39

References ...................................40 
Chapter 2

Auditory Forebrain Organization: Thalamocortical and Corticothalamic Connections in the Cat ........43 Michael M. Merzenich, Steve A. Colwell and Richard A. Andersen

1. Introduction $\ldots \ldots \ldots \ldots \ldots \ldots \ldots \ldots \ldots \ldots \ldots \ldots \ldots \ldots$

1.1. Redefinition of Auditory Cortical Fields in the

Cat ...............................44

1.2. Internal Organization of Auditory Cortical

Fields.................................44

1.3. Internal Organization of the Medial

Geniculate Body (MGB) ...................47

2. Basic Approach...............................47

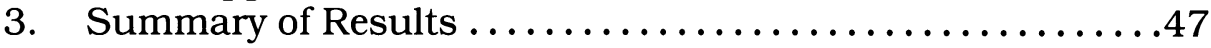

3.1. Geometry of Arrays of Neurons Projecting

from MGB to A I .......................47

3.2. Banding of the MGB Ventral Division

Projection............................51

3.3. Descending Corticothalamic Projections from

A I to the MGB..........................53

3.4. Interconnections of MGB Nuclei with Other

Cortical Fields.............................53

4. Conclusions ...................................53

Acknowledgments ...............................55

References ................................55

Chapter 3

Auditory Cortical Areas in Primates .......... 59 John F. Brugge

1. Early Studies in Monkeys, Apes and Humans ............59

2. Microelectrode Studies of the Organization of

Primate Auditory Cortex $\ldots \ldots \ldots \ldots \ldots \ldots \ldots \ldots \ldots \ldots .62$

Acknowledgments ...............................69



Chapter 4

Organization of Auditory Connections: The

Primate Auditory Cortex....................71

\section{Kathleen A. FitzPatrick and Thomas J. Imig}

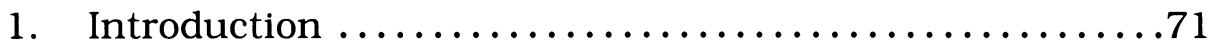

2. Cytoarchitecture of the Medial Geniculate Body ..........73

3. Projections to the Medial Geniculate .................75 
4. Projections to Other Thalamic Nuclei $\ldots \ldots \ldots \ldots \ldots \ldots . . .81$

5. Projections to the Inferior Colliculus ................82

6. Cortical Projections.......................... 85

7. Ipsilateral Cortical Projections.................. 85

8. Contralateral Cortical Projections...................93

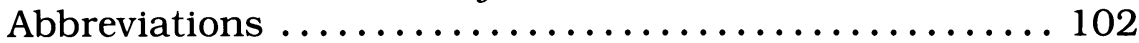

References ........................... 103

Chapter 5

Polysensory "Association" Areas of the

Cerebral Cortex: Organization of Acoustic

Input in the Cat ........................ 111

D. R. F. Irvine and D. P. Phillips

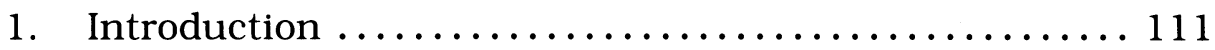

1.1. Cortical Association Areas and Hypothesized

Sources of Sensory Input ............... 111

1.2. Lesion Studies of Acoustic Input and the

Question of Specific Receptive-Field

Properties.......................... 114

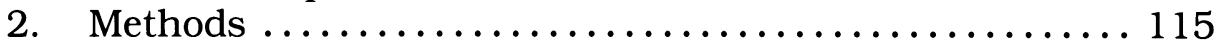

3. Acoustic Properties of Neurons in Cortical

Association Fields ....................... 116

3.1. General Response Properties .............. 116

3.2. Frequency Tuning and Thresholds .......... 118

3.3. Binaural Properties................... 120

4. The Nonspecific Projection System .............. 122

4.1. Acoustic Input to Medial/Intralaminar

Thalamus........................ 122

4.2. Cortical Projections from Medial/Intralaminar

Thalamus......................... 129

4.3. The Mesencephalic Reticular Formation:

Acoustic Input and Connections .......... 130

4.4. Conclusions and Commentary ............. 131

5. The Auditory "Lemniscal Adjunct" System ........... 132

5.1. The "Lemniscal Line"/"Lemniscal Adjunct"

Distinction........................ 132

5.2. The Pulvinar-Posterior Complex: Acoustic

Input and Connections ................ 133

5.3. Possible Input from Auditory Cortex .......... 138

6. Chloralose Anesthesia and the Functional

Interpretation of the Data .................... 139

7. Conclusions and Final Considerations............. 143

Acknowledgments ........................ 145

References ............................. 145 
Chapter 6

\section{Functional Organization of the Auditory}

Cortex: Representation Beyond Tonotopy in the

Bat.............................. 157

\section{Nobuo Suga}

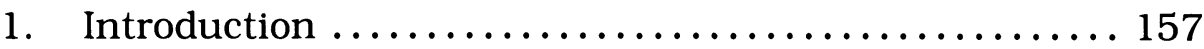

1.1. Hypotheses and Neurophysiology of Cortical

Representation of Auditory Information ...... 157

1.2. Unique Aspects of the Biosonar Signals and the Peripheral Auditory System of the

Mustached Bat...................... 163

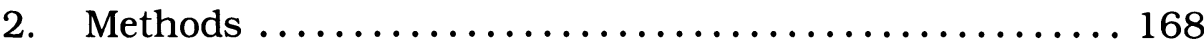

2.1. Materials............................ 168

2.2. Surgery .......................... 168

2.3. Animals During Experiments $\ldots \ldots \ldots \ldots \ldots \ldots \ldots 168$

2.4. Acoustic Stimuli........................ 168

2.5. Data Acquisition ..................... 169

2.6. Anesthetics and Neural Activity ............. 169

3. Results and Discussion ..................... 170

3.1. Areas Specialized for Processing Biosonar Information in the Cerebrum ............. 170

3.2. Extraction of Information-Bearing Elements and Examination of Their Combinations ...... 200

3.3. Specialized and Unspecialized Neurons ......... 205

3.4. Parallel-Hierachical Processing............. 206

3.5. Specialized Neurons as IBP Filters........... 208

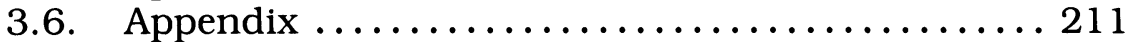

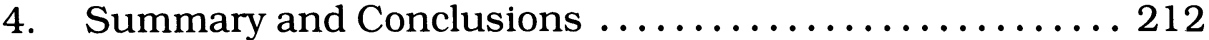

Acknowledgments ......................... 214

References .............................. 214

Chapter 7

A Theory of Neural Auditory Space: Auditory

Representation in the Owl and Its Significance . . . . . 219 Masakazu Konishi and Eric I. Knudsen

1. Introduction . .......................... 219

2. Perception of Auditory Space................. 220

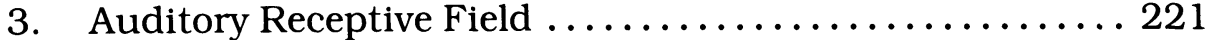

4. A Neural Map of Auditory Space ................ 225

5. Functional Division within the Auditory Midbrain...... 226

6. Concluding Remarks . .................... 226

Acknowledgments .......................... 228

References ............................. 228 
Chapter 8

Cortical Auditory Area of Macaca mulatta and Its Relation to the Second Somatic Sensory

Area (SM II): Determination by Electrical

Excitation of Auditory Nerve Fibers in the Spiral

Osseous Lamina and by Click Stimulation......... 231

C. N. Woolsey and E. M. Walzl

1. Introduction ................................. 232

2. Materials and Methods........................ 232

3. Results............................... 235

3.1. Cortical Area Responsive to Clicks............. 235

3.2. Topical Projection of Nerve Fibers from Local

Regions of the Cochlea to the Cerebral

Cortex ............................. 237

3.3. The Second Somatic Sensory Area............ 241

4. Discussion ................................ 246

4.1. The Auditory Cortex as Defined by These

Experiments ....................... 246

4.2. More Recent Studies of Auditory Cortex in

Primates........................... 248

4.3. Homologies of Auditory Areas in Cat and

Monkey .......................... 250

4.4. The Second Somatic Sensory Area of the

Monkey and Its Relation to the Auditory

Area ............................... 252

Acknowledgments ............................. 253

References ................................. 253

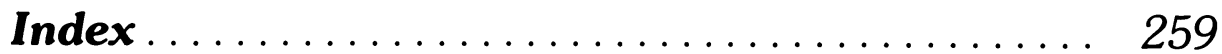




\section{Contents of Other Volumes}

Volume 1: Multiple Somatic Areas

The Somatic Sensory Cortex: Sm I in Prosimian Primates, Mary Carlson and Carol Welt

The Postcentral Somatosensory Cortex: Multiple Representations of the Body in Primates, John H. Kaas, Mriganka Sur, Randall J. Nelson and Michael M. Merzenich

Organization of the S I Cortex: Multiple Cutaneous Representations in Areas $3 \mathrm{~b}$ and 1 of the Owl Monkey, Michael M. Merzenich, Mriganka Sur, Randall J. Nelson and Jon H. Kass

Organization of the S II Parietal Cortex: Multiple Somatic Sensory Representations within and near the Second Somatic Sensory Area of Cynomolgus Monkeys, $\boldsymbol{H}$. Burton and C. J. Robinson

Body Topography in the Second Somatic Sensory Area: Monkey S II Somatotopy, David P. Friedman

Supplementary Sensory Area: The Medial Parietal Cortex, Elisabeth A. Murray and Joe D. Coulter

Spatial Organization of the Primate Precentral Cortex: Quantitative Neighborhood Relations, H. C. Kwan, J. T. Murphy and Y. C. Wong

Intracortical Connectivities of Somatic Sensory and Motor Areas: Multiple Cortical Pathways in Monkeys, R. M. Bowker and J. D. Coulter

\section{Volume 2: Multiple Visual Areas}

Multiple Cortical Visual Areas: Visual Field Topography in the Cat, R. J. Tusa, L. A. Palmer and A. C. Rosenquist

Comparative Studies on the Visual Cortex, Vicente M. Montero

Multiple Representations of the Visual Field: Corticothalamic and Thalamic Organization in the Cat, B. V. Updyke

Families of Related Cortical Areas in the Extrastriate Visual System: Summary of an Hypothesis, Ann M. Graybiel and David M. Berson 
Cortical and Subcortical Connections of the Visual Cortex in Primates, Rosalyn E. Weller and Jon H. Kaas

Organization of Extrastriate Visual Areas in the Macaque Monkey, D. C. Van Essen, J. H. R. Maunsell and J. L. Bixby

Visual Topography and Function: Cortical Visual Areas in the Owl Monkey, John M. Allman, James F. Baker, William T. Newsome and Steven E. Petersen

Cortical Visual Areas of the Temporal Lobe: Three Areas in the Macaque, C. G. Gross, C. J. Bruce, R. Desimone, J. Fleming and R. Gattass 


\section{Preface}

In April 1979 a symposium on "Multiple Somatic Sensory Motor, Visual and Auditory Areas and Their Connectivities" was held at the FASEB meeting in Dallas, Texas under the auspices of the Committee on the Nervous System of the American Physiological Society. The papers presented at that symposium are the basis of most of the substantially augmented, updated chapters in the three volumes of Cortical Sensory Organization. Only material in chapter 8 of volume 3 was not presented at that meeting.

The aim of the symposium was to review the present status of the field of cortical representation in the somatosensory, visual and auditory systems. Since the early 1940s, the number of recognized cortical areas related to each of these systems has been increasing until at present the number of visually related areas exceeds a dozen. Although the number is less for the somatic and auditory systems, these also are more numerous than they were earlier and are likely to increase still further since we may expect each system to have essentially the same number of areas related to it.

Discovery of second somatic, visual and auditory areas in the early 1940s followed soon after the development of the evoked potential method for the study of cortical localization. The great increase in the number of recognized areas in the last 10 years has resulted from the use of microelectrode recordings from small clusters of neurons and from single units, which permit far more detailed examination of the brain than did the technology of earlier years. Other factors have been the study of more lightly anesthetized animals and of unanesthetized animals, whose brains have been explored through chambers implanted over the areas to be studied. One can expect the number of recognized areas to increase as more of the cortical surface is explored in detail in various species of animals.

Most individual studies to date have dealt with a single system for which the investigators have developed specialized equipment and skills in its study. There is evidence, however, that some cortical areas may respond to more than one modality of sensory input. This is particularly true of the so-called "association" cortex of the suprasylvian gyrus of the cat. It now seems very desirable to explore 
under optimal conditions all cortical areas with stimuli of more than one sensory modality. This will require that investigators acquire sophisticated equipment for the study of somatic, visual and auditory systems and develop skills in its use. An alternative method would be for experts on each system to join forces, so that the methods specialized for the three systems can be applied in a single given experiment.

Increasing quantities of information on the organization of afferent and efferent systems are being derived from the application of techniques for the study of connectivities within the central nervous system, through the use of tritiated amino acids and horseradish peroxidase, as illustrated by several of the studies reported in these volumes.

An important area of research not covered in these volumes is the study of behaving animals with implanted recording electrodes. I foresee that ultimately all areas of the cortex will be examined in this way.

Another area requiring study is the sensory input to the cortical motor areas. Corticocortical connections to these areas have been studied, as reported in volume 1, but more detailed sensory input using electrophysiological methods have not yet defined the sensory inputs to the precentral and supplementary motor areas. Similarly, less work has been done on the motor output from the postcentral sensory areas and its relation to the sensory input to these areas. There is practically no modern work on the effects of electrical stimulation of the visual and auditory areas of the cortex, although motor effects were obtained on stimulation of these areas by Ferrier and other early students of cortical localization.

An important problem for the future concerns the terminology to be applied to the many new cortical areas. If these areas correspond to recognized cytoarchitectural areas of Brodmann, that terminology should be applied. At present there is considerable confusion in terminology, perhaps best illustrated by the terms used to describe the various auditory areas in cat and monkey, where terms for the cat are related to the position of the areas in the auditory region. However, because the auditory region changes its orientation with evolution, the same terms used for cat cannot be used for the monkey. Perhaps when all areas have been identified and their corticortical connections and relations with subcortical structures have been fully defined, a more rational terminology can be proposed.

The three volumes of this work do not include reports from all the important workers in the fields surveyed. It was not possible in the time available to the symposium to include all those we should have liked to invite. 
The editor wishes to express his deep appreciation to all those who took part in the Dallas symposium, and to thank them for the manuscripts which they prepared for these three volumes on Cortical Sensory Organization. He is also grateful to Drs. J. C. Coulter, J. H. Kaas and J. F. Brugge, who chaired the three programs. Finally, special thanks is due to Thomas Lanigan of the Humana Press for his interest in publishing this work and the care that he has devoted to seeing the material through the press.

The editor also wishes to thank Evadine Olson for several typing tasks that she performed in relation to his editorial functions. 